\title{
Sodium Glucose Co-Transporter-2 (SGLT2) Inhibitors: A Review of Their Basic and Clinical Pharmacology
}

Sanjay Kalra

To view enhanced content go to www.diabetestherapy-open.com

Received: August 21, 2014 / Published online: November 26, 2014

(c) The Author(s) 2014. This article is published with open access at Springerlink.com

\section{ABSTRACT}

Sodium-glucose co-transporter-2 (SGLT2) inhibitors are a newly developed class of oral anti-diabetic drugs (OADs) with a unique mechanism of action. This review describes the biochemistry and physiology underlying the use of SGLT2 inhibitors, and their clinical pharmacology, including mechanism of action and posology. The pragmatic placement of these molecules in the existing $\mathrm{OAD}$ arena is also discussed.

Keywords: Anti-diabetic drugs; Cardiovascular safety; Canagliflozin; Dapagliflozin; Empagliflozin; Perineal hygiene; Sodiumglucose co-transporter-2 inhibitors

Electronic supplementary material The online version of this article (doi:10.1007/s13300-014-0089-4) contains supplementary material, which is available to authorized users.

S. Kalra $(\bowtie)$

Bharti Hospital and B.R.I.D.E., Karnal, India e-mail: brideknl@gmail.com

\section{INTRODUCTION}

Healthy individuals are able to maintain tight glucose homeostasis by closely regulating glucose production, reabsorption, and utilization. The importance of this homeostatic mechanism is evident from the fact that, in spite of extreme variations in glucose intake, relatively few people develop either diabetes or hypoglycemia [1].

In people without diabetes, about $180 \mathrm{~g}$ of glucose is filtered daily by the renal glomeruli, and is then reabsorbed in the proximal convoluted tubule (PCT). This is achieved by passive transporters, namely, facilitated glucose transporters (GLUTs), and active cotransporters, namely, sodium-glucose cotransporters (SGLTs). There are six identified SGLTs, of which two (SGLT1 and SGLT2) are considered most important [1]. These SGLTs are described in Table 1 [2].

This review describes the biochemistry and physiology underlying the use of SGLT2 inhibitors (SGLT2i), and their clinical pharmacology, including mechanism of action and posology, and discusses the pragmatic placement of these molecules in the existing oral anti-diabetic drug arena. The article is based 
Table 1 Comparison of SGLT1 and SGLT2

\begin{tabular}{lll}
\hline Characteristic & SGLT1 & SGLT2 \\
\hline Location & $\begin{array}{c}\text { Small intestine; later part of PCT } \\
(\text { segment 3) }\end{array}$ & Early PCT (segment 1, 2) \\
Capacity & Low & High \\
Affinity & High & Low \\
Contribution to glucose reabsorption & $10 \%$ & $90 \%$ \\
Disease state if mutation/deficiency occurs & Glucose-galactose malabsorption & Familial renal glucosuria \\
Physical manifestations of disease state & Diarrhea at few days age & None \\
Course & Fatal without glucose free/galactose & Benign \\
Inhibitors & free diet & Currently available SGLT2i \\
\hline
\end{tabular}

PCT proximal convoluted tubule, $S G L T$ sodium-glucose co-transporter, $S G L T 2 i$ sodium-glucose co-transporter-2 inhibitors

on previously conducted studies, and does not involve any new studies of human or animal subjects performed by the author.

\section{HISTORY}

The first SGLT2i discovered was phlorizin, a naturally occurring compound derived from apple tree bark. Because of its non-selective nature, it caused severe gastrointestinal symptoms. Due to this and to its poor oral bioavailability, work on its development could not continue [3]. Drugs which specifically inhibit SGLT2, and thereby avoid gastrointestinal effects related to SGLT1 inhibition, have now been developed, some of which are listed in Table 2.

\section{RATIONALE}

Glucosuria (i.e., the excretion of glucose through the kidneys) only occurs if the maximal capacity of various glucose transporter proteins (350 $\mathrm{mg}$ glucose/min) is exceeded [2, 4]. Earlier, glucosuria was thought
Table 2 Sodium glucose co-transporters in advanced development or already approved

\begin{tabular}{ll}
\hline Molecule & Approval/development status \\
\hline Canagliflozin & $\begin{array}{c}40 \text { countries including EU, USA, } \\
\text { China, Russia }\end{array}$ \\
Dapagliflozin & $\begin{array}{l}40 \text { countries including EU, USA, } \\
\text { Japan, }\end{array}$ \\
Empagliflozin & Phase $3[37]$ \\
Ipragliflozin & Japan \\
Luseogliflozin & Under review for approval in Japan \\
Tofogliflozin & Phase 3 [43, 44] \\
\hline
\end{tabular}

to be a pathological mechanism, or a marker of illness. However, one may approach this condition from a different view point. Persons with ambient hyperglycemia are at risk of endothelial dysfunction and resultant complications, due to the high levels of glucose in circulation. Kidneys try to prevent an excessive rise in blood glucose levels by glucuresis, thereby mitigating the adverse effects associated with high glucose levels. Theoretically, compounds which promote glucuresis should help to reduce circulating 
glycemia, manage diabetes, and prevent longterm complications.

\section{MECHANISM OF ACTION}

Sodium-glucose co-transporter-2 inhibitors work by inhibiting SGLT2 in the PCT, to prevent reabsorption of glucose and facilitate its excretion in urine. As glucose is excreted, its plasma levels fall leading to an improvement in all glycemic parameters [4-6].

This mechanism of action is dependent on blood glucose levels and, unlike the actions of thiazolidinediones (mediated through GLUTs), is independent of the actions of insulin. Thus, there is minimal potential for hypoglycemia, and no risk of overstimulation or fatigue of the beta cells [7]. Because their mode of action relies upon normal renal glomerular-tubular function, SGLT2i efficacy is reduced in persons with renal impairment.

\section{CLINICAL PHARMACOLOGY}

Dapagliflozin is rapidly absorbed after oral administration, reaching peak plasma concentration in $2 \mathrm{~h}$, and exhibiting oral bioavailability of $78 \%$ [8]. Dapagliflozin is metabolized by uridine diphosphateglucuronosyltransferase (UGT)1A9 in both the liver and kidneys [8]. Canagliflozin achieves maximal plasma concentration $1-2 \mathrm{~h}$ after oral administration (oral bioavailability 65\%) and steady state after $4-5$ days. It is metabolized by glucuronidation by UGT1A9 and UGT2B4 [9]. Empagliflozin reaches peak plasma concentration $1.33-3.0 \mathrm{~h}$ after oral administration, before declining in a biphasic manner. The terminal half-life has been calculated to be $10.3-18.8 \mathrm{~h}$ in multiple dose studies, with steady state being achieved by day
6 [10]. No dosage adjustments are required in renal or hepatic impairment. A summary of the clinical pharmacology of SGLT2i is presented in Table 3.

Dapagliflozin and canagliflozin have proven efficacy in improving glycemic parameters, both as monotherapy and in combination [11]. A 52-week comparison between canagliflozin 100 and $300 \mathrm{mg}$ showed noninferiority, and canagliflozin $300 \mathrm{mg}$ showed statistical superiority to sitagliptin in lowering glycated hemoglobin (HbA1c) [12]. Canagliflozin $100 \mathrm{mg}$ and $300 \mathrm{mg}$ reduced bodyweight versus placebo at week 26 and sitagliptin at week 52 . The published results are summarized in Table 4. Four-year (208week) use of dapagliflozin with metformin produced a sustained and durable reduction in blood glucose levels with significantly less frequent adverse reactions as compared to glimepiride with metformin. After 4 years, the difference in HbA1c reduction between two groups was $-0.3 \%$ [95\% confidence interval (CI) $-0.51,-0.09]$. The trend over a period of time showed further increase in the difference with more prolonged use [13].

The long-term efficacy and safety of empagliflozin have also been investigated as add-on therapy to basal insulin. Patients with type 2 diabetes mellitus (T2DM) were randomized to receive empagliflozin 10 or $25 \mathrm{mg}$ once daily or placebo; the basal insulin regimen was kept constant for the first 18 weeks, after which the treating investigator could adjust the regimen at their discretion for the following 60 weeks [14]. As well as significant improvements in $\mathrm{HbA1c}$, patients in both of the empagliflozin groups had significant reductions in their insulin doses at week 78, and also registered weight loss versus a small weight gain in those receiving placebo [14]. The decrease in insulin requirements in 
Table 3 Clinical pharmacology of sodium-glucose co-transporter-2 inhibitors

\begin{tabular}{|c|c|c|c|c|}
\hline Molecule & Dose range & $\begin{array}{l}\text { Oral } \\
\text { bioavailability } \\
(\%)\end{array}$ & Elimination pathway & Dose modifications \\
\hline Dapagliflozin & $\begin{array}{l}\text { 5-10 mg } \\
\text { once daily }\end{array}$ & 78 & $\begin{array}{l}\text { Hepatic and renal } \\
\text { UGT1A9 }\end{array}$ & $\begin{array}{l}\text { Should not be initiated in patients with } \\
\text { eGFR }<60 \mathrm{ml} / \mathrm{mt} / 1.73 \mathrm{~m}^{2} \\
\text { No dose adjustment in patients with } \\
\text { eGFR }>60 \mathrm{ml} / \mathrm{min} / 1.73 \mathrm{~m}^{2}\end{array}$ \\
\hline Canagliflozin & $\begin{array}{c}100-300 \mathrm{mg} \\
\text { once daily }\end{array}$ & 65 & UGT1A9 and 2B4 & $\begin{array}{l}\text { Dose limited to } 100 \mathrm{mg} \text { once daily in patients } \\
\text { with eGFR }>45<60 \mathrm{ml} / \mathrm{min} / 1.73 \mathrm{~m}^{2} \\
\text { Stopped in patients with eGFR }<45 \mathrm{ml} / \mathrm{min} / \\
1.73 \mathrm{~m}^{2}\end{array}$ \\
\hline Empagliflozin & $\begin{array}{l}10-25 \mathrm{mg} \\
\text { once daily }\end{array}$ & $\mathrm{N} / \mathrm{a}$ & $\begin{array}{l}\text { UGT1A3, UGT1A8, } \\
\text { UGT1A9, and } \\
\text { UGT2B7 }\end{array}$ & $\begin{array}{l}\text { Dose adjustment in patients with creatinine } \\
\text { clearance }<60 \mathrm{ml} / \mathrm{min} \\
\text { Contraindicated in patients with creatinine } \\
\text { clearance }<45 \mathrm{ml} / \mathrm{min} \\
\text { No adjustment in hepatic failure }\end{array}$ \\
\hline Ipragliflozin & $\begin{array}{c}100-300 \mathrm{mg} \\
\text { once daily }\end{array}$ & 65 & $\begin{array}{l}\text { UGT1A9 and } \\
\text { UGT2B4 }\end{array}$ & $\begin{array}{l}\text { Dose limited to } 100 \mathrm{mg} \text { once daily in patients } \\
\text { with eGFR }>45<60 \mathrm{ml} / \mathrm{min} / 1.73 \mathrm{~m}^{2} \\
\text { Not recommended in patients with } \\
\text { eGFR }<45 \mathrm{ml} / \mathrm{min} / 1.73 \mathrm{~m}^{2}\end{array}$ \\
\hline
\end{tabular}

$e G F R$ estimated glomerular filtration rate, $N / a$ not available, $U G T$ uridine diphosphate-glucuronosyltransferase

patients on dapagliflozin has been evaluated in a study on insulin-mediated whole-body glucose uptake and endogenous glucose production using euglycemic hyperinsulinemic clamp technique. Dapagliflozin treatment for 2 weeks increased insulin-mediated tissue glucose disposal by $18 \%$ and resulted in an increase in endogenous glucose production (with increased fasting glucagon levels) [15].

\section{PLEIOTROPIC EFFECTS}

Sodium-glucose co-transporter-2 inhibitors use leads to a reduction in body weight, ranging from about 1 to $5 \mathrm{~kg}$ [16]. A greater fall is seen in patients with long-standing diabetes and in those with a higher baseline weight. This weight loss is sustained after up to 2 years of use of dapagliflozin, and may be linked to a reduction in insulin dose requirements of patients with long-standing diabetes [16]. Analysis of 208-week data comparing dapagliflozin in combination with metformin versus glimepiride in combination with metformin showed $4.38 \mathrm{~kg}$ (95\% CI -5.31, -3.46) difference between two groups. Patients in the glimepiride group gained a mean of $0.73 \mathrm{~kg}$ while those in dapagliflozin group lost $3.65 \mathrm{~kg}$ [13].

While it may be argued that weight loss is because of volume depletion, it has been shown that two-thirds of the decreased weight is lost from fat mass (especially visceral abnormal fat), as compared to lean mass [14]. An initially rapid 
Table 4 Glucose-lowering efficacy of sodium-glucose co-transporter-2 inhibitors

\begin{tabular}{|c|c|c|c|c|c|c|c|c|}
\hline \multirow{2}{*}{$\begin{array}{l}\text { Molecule } \\
\text { (duration of } \\
\text { study) }\end{array}$} & \multirow[t]{2}{*}{ Parameter } & \multirow[t]{2}{*}{ Monotherapy } & \multicolumn{5}{|c|}{ Combination with other oral anti-diabetic drugs } & \multirow{2}{*}{$\begin{array}{l}\text { As add- } \\
\text { on to } \\
\text { insulin }\end{array}$} \\
\hline & & & $\begin{array}{l}\text { Initial } \\
\text { combination } \\
\text { with Met }\end{array}$ & $\begin{array}{l}\text { With } \\
\text { Met }\end{array}$ & $\begin{array}{l}\text { With } \\
\text { SU }\end{array}$ & $\begin{array}{l}\text { With } \\
\text { Met + SU }\end{array}$ & $\begin{array}{l}\text { With } \\
\text { Met + TZD }\end{array}$ & \\
\hline \multirow{3}{*}{$\begin{array}{l}\text { Canagliflozin } \\
300 \mathrm{mg} \\
\text { (26-week study) }\end{array}$} & HbAlc (\%) & -1.03 & - & -0.94 & -0.79 & -1.06 & -1.03 & -0.72 \\
\hline & $\mathrm{FPG}(\mathrm{mg} / \mathrm{dl})$ & -35 & - & -27 & - & -31 & -33 & -25 \\
\hline & PPG (mg/dl) & -59 & - & -48 & - & - & - & - \\
\hline \multirow{3}{*}{$\begin{array}{l}\text { Dapagliflozin } \\
10 \mathrm{mg} \\
\text { (24-week study) }\end{array}$} & HbAlc (\%) & -0.9 & -2.0 & -0.8 & -0.8 & -1.0 & -0.4 & -0.9 \\
\hline & $\mathrm{FPG}(\mathrm{mg} / \mathrm{dl})$ & -28.8 & -60.4 & -23.5 & -28.5 & -29.6 & -24.1 & -21.7 \\
\hline & PPG (mg/dl) & - & - & - & -60.6 & -67.5 & - & - \\
\hline Ipragliflozin & HbAlc $(\%)$ & -1.29 & - & -0.48 & -1.14 & -0.88 & - & - \\
\hline $\begin{array}{l}300 \mathrm{mg} \\
\text { (24 week study) }\end{array}$ & $\mathrm{FPG}(\mathrm{mg} / \mathrm{dl})$ & -39.4 & - & - & -38 & -41 & - & - \\
\hline
\end{tabular}

FPG fasting plasma glucose, HbAlc glycated hemoglobin, Met metformin, MetXR metformin extended release, PPG postprandial plasma glucose, $S U$ sulfonylurea, $T Z D$ thiazolidinedione

decline in weight is followed by a slower rate of weight loss, and is also marked by a reduction in weight circumference. Concomitant use of SGLT2i can attenuate or neutralize weight gain due to insulin, if given in combination with insulin [16].

Sodium-glucose co-transporter-2 inhibitors also cause significant reductions in both systolic and diastolic blood pressure (BP). These changes are relatively more prominent for systolic BP, are not dose dependent, and are not characterized by concomitant tachycardia or symptoms of hypotension/syncope in most of the cases. The effects on BP seem to be independent of glycemic or body weight reduction, and are greater in patients with high baseline systolic BP [17]. BP reduction with SGLT2i occurs due to osmotic diuresis initially, and to local rennin-angiotensin system inhibition later on [18]. Some studies have reported reduction of up to $13.4-17 \mathrm{mmHg}$ in systolic BP with empagliflozin, a magnitude similar to that observed with many antihypersensitive drugs [19, 20]. A recently published 104-week outcome study of canagliflozin showed that the 100 and $300 \mathrm{mg}$ dose reduced systolic and diastolic BP compared with glimepiride, with no notable changes in pulse rate [20]. Analysis of 208-week data comparing dapagliflozin in combination with metformin versus glimepiride with metformin showed an increase of $0.2 \mathrm{mmHg}$ (95\% CI $-1.66,1.61)$ in the glimepiride group while those on dapagliflozin showed a reduction of $3.69 \mathrm{mmHg}(95 \% \mathrm{CI}-5.24,-2.14)$ [13].

Sodium-glucose co-transporter-2 inhibitors are either lipid-friendly or lipid-neutral drugs. Canagliflozin, for example, increases highdensity lipoprotein (HDL) by 7.1-10.6\%, lowdensity lipoprotein (LDL) by $7.1 \%$, and reduces triglycerides by $2.3 \%[21,22]$. Treatment with canagliflozin for 104 weeks was also associated with increases in HDL-C and LDL-C, which is consistent with findings at week 52. However, the proportion of patients who started or modified therapy with lipid-modifying agents were $13 \%, 11.5 \%$, and $13.3 \%$ in the canagliflozin $100 \mathrm{mg}$, canagliflozin $300 \mathrm{mg}$, 
and glimepiride groups, respectively [23]. After 4 years of use, sustained and stable weight loss was observed with dapagliflozin versus weight gain with glimepiride (-3.95 vs. $+1.12 \mathrm{~kg})$. Mean systolic BP was reduced with dapagliflozin but not with glimepiride [24].

Data from 21 clinical studies, including 2 that exclusively enrolled patients with a history of cardiovascular disease (CVD), were included in a prespecified meta-analysis $(n=9,339)$ to assess the cardiovascular (CV) safety of dapagliflozin $\quad(2.5 \mathrm{mg} \quad$ to $>10 \mathrm{mg} /$ day; $n=5,936$ ) versus comparators (placebo or active $n=3$,403) [25]. The prespecified primary end point was a composite of time to $\mathrm{CV}$ death, myocardial infarction (MI), stroke, or hospitalization for unstable angina. The secondary end point included the primary end point plus unplanned coronary revascularization and hospitalization for heart failure. The estimated hazard ratio (HR) using a Cox proportional hazards method was 0.787 $(95 \%$ CI $0.579,1.070)$. Analyses of the secondary end point (HR 0.758; 95\% CI 0.581, 0.988 ) and of an ad-hoc major adverse CV events composite end point of $\mathrm{CV}$ death, MI, and stroke (HR 0.772; 95\% CI 0.543, 1.097) were consistent with the primary end point results. These findings suggest that there is no increase in $\mathrm{CV}$ risk associated with dapagliflozin in an updated $\mathrm{CV}$ risk analysis that includes more patients and a substantial proportion of older patients $(>20 \%)$ and patients with established CVD (>30\%). Although these results are encouraging, presently the evidence is lacking regarding macro and micro-vascular complications of T2DM in patients managed with this class of drugs. A randomizedcontrolled clinical trial is already underway to explore the long-term CV outcomes in patients on treatment with SGLT2i as primary end point [26].
Uric acid levels, a marker of metabolic dysfunction, are markedly reduced (5.9-17.8\%) by SGLT2i, with the effect sustained for 2 years [27]. The drugs may affect uric acid excretion directly, by acting on its transport system, or indirectly, but reducing sodium reabsorption in the PCT. The beneficial impact of SGLT2i on uric acid is attenuated if insulin is co-prescribed.

Renal hyperfiltration has been found to be closely associated with the development of diabetic nephropathy (DN) [28]. Pooled data from 2 randomized clinical trials including 600 patients with normo- or microalbuminuria followed up for 4 years which demonstrated that hyperfiltration has central role in pathogenesis of DN [28]. SGLT2 is one of the main determinants of glomerular hyperfiltration and blockade of SGLT2 has potential nephroprotective action.

\section{POSOLOGY}

Dapagliflozin is approved as $10 \mathrm{mg}$ once-daily drug, as monotherapy, or as add-on to metformin, sulfonylurea (SU), dipeptidyl peptidase-4 (DPP-4) inhibitors, and/or insulin. It can be prescribed alone to persons who do not tolerate or cannot take metformin safely. A 5 -mg dose is available for persons with hepatic insufficiency. In mild to moderate hepatic impairment, no dosage adjustment is required. However, in severe hepatic impairment, $5 \mathrm{mg}$ starting dose is recommended [29].

Canagliflozin has a two-stage dosage regime. The starting dose approved is $100 \mathrm{mg}$ once daily, before the first meal of the day. In those who do not respond adequately, the dose can be increased to $300 \mathrm{mg}$, provided renal function is normal [10].

Empagliflozin is being studied in daily doses of 10 and $25 \mathrm{mg}$. Trials have revealed dosedependent HbA1c reductions with 
empagliflozin monotherapy, which are greater as compared to those observed with sitagliptin, but similar to those experienced with metformin. Empagliflozin can be administered without relation to meal timings, in a oncedaily frequency [30].

Ipragliflozin has Japanese approval for the treatment of T2DM, either alone or in combination with metformin, pioglitazone, SU, $\alpha$-glucosidase inhibitor, DPP-4 inhibitor, or with nateglinide [30].

\section{ADVERSE EVENTS}

The incidence of adverse events in clinical trials of SGLT2i is similar to that observed with other anti-diabetic drugs. The overall incidence of adverse events has ranged from 57.3 to $83.0 \%$, while that of serious adverse events have varied between $1.0 \%$ and $12.6 \%$ [31].

Uro-genital tract infections are the most frequently noticed adverse events in subjects on SGLT2i [32], especially in women and in uncircumcised men. Pooled data from 12 placebo-controlled clinical trials of dapagliflozin reveal that when used in dose $2.5,5$, and $10 \mathrm{mg}$ per day, the incidence of clinically diagnosed uro-genital tract infection was $4.1 \%, 5.7 \%$ and $4.8 \%$, respectively, while it was $0.9 \%$ in the placebo group [33]. Common infections include vulvitis and vulvo-vaginitis in women, as well as balanitis and balanoposthitis in men. These can be prevented by maintaining adequate perineal hygiene, and through treatment with antifungal therapy. Genital infections are thought to be caused by an increased glucose load in the urinary tract, which encourages fungal growth. The incidence of urinary tract infections does not increase with SGLT2i therapy [34].
The osmotic diuresis associated with SGLT2i use also has the potential to cause volume depletion and orthostatic hypotension. In randomized-controlled trials, however, the incidence of these adverse events has been minimal $(<3 \%)$ [25]. All such events have been mild to moderate in severity. The extra diuresis experienced per day is $350-450 \mathrm{ml}$ (one extra void per day) [34], and does not cause nocturia. The diuresis seen with SGLT2i may result in slight transient increase in serum creatinine and blood urea, with a corresponding fall in glomerular filtration rate (GFR).

The risk of hypoglycemia is minimal with SGLT2i, as they have a non-insulin-based mechanism of action. However, hypoglycemia may occur when these molecules are used in complication with other anti-diabetic drugs, including metformin. Four-year comparison between dapagliflozin plus metformin and glipizide plus metformin showed a tenfold decrease in the incidence of hypoglycemic episodes (5.4\% and 51.5\%, respectively) [13]. In this 208-week study, patients treated with dapagliflozin plus metformin had 35 hypoglycemic events as compared to 1,191 events in glipizide plus metformin group. Dose-down titration during first year was required in $2.7 \%$ patients in the dapagliflozintreated group compared with $15.8 \%$ in the glipizide-treated group. This finding is very significant in light of the long-term consequences of hypoglycemic episodes on the physiology of patients and their compliance to treatment.

Sodium-glucose co-transporter-2 inhibitors use leads to a slight reduction in bone formation, and a rise in bone resorption markers, although there are no major changes on bone mineral density. A 102-week study with dapagliflozin did not identify any changes in markers of bone turnover as compared to 
placebo when added to metformin [27]. Other long-term studies have not demonstrated any significant increase in adverse drug reactions related with skeletal system with any of the SGLT2i [35, 36].

\section{USE IN RENAL IMPAIRMENT}

In patients with reduced GFR, the amount of glucose reaching the PCT falls and the efficacy of SGLT2 may be suboptimal. Canagliflozin is prescribed in a full dose of $300 \mathrm{mg}$ daily if GFR is above $60 \mathrm{ml} / \mathrm{min}$ and as $100 \mathrm{mg}$ once daily if GFR is $45-60 \mathrm{ml} / \mathrm{min}$ [10]. Dapagliflozin can be prescribed as 5 or $10 \mathrm{mg}$ once daily, depending upon the regulatory label in the country concerned [29]. A pooled analysis of 13 clinical trials exploring the long-term renal safety of dapagliflozin $10 \mathrm{mg}$ as compared to placebo or other oral hypoglycemic agents showed no change in renal functions over a period varying from 12 to 104 weeks [25]. Similarly, empagliflozin is being studied in doses of 10 and $25 \mathrm{mg}$ per day [37].

\section{DRUG-DRUG INTERACTIONS}

Sodium-glucose co-transporter-2 inhibitors do not exhibit any clinically relevant drug-drug interactions, including with other anti-diabetic drugs and diuretics. They can be combined with metformin, SU, pioglitazone, sitagliptin, and voglibose. Concomitant prescription of loop diuretics and SGLT2i should be avoided because of the potential risk for volume depletion. Co-administration of canagliflozin with UGT-inducer drugs, for example, rifampicin, phenytoin, phenobarbitone, and ritonavir, should prompt an increase in dose from 100 to $300 \mathrm{mg}$, if otherwise tolerated [10]. UGT enzyme-inducing agents increase the metabolism of canagliflozin thus leading to a decrease in peak plasma levels and reduced efficacy [32].

\section{CLINICAL USE}

Current management of diabetes is characterized by opportunities, options, and obstacles. In spite of the availability of a wide array of oral and injectable options, it remains difficult to achieve good glycemic control, while avoiding hypoglycemia and weight gain, and ensuring CV safety. These adverse effects are obstacles to the optimal use of pharmaceuticals options currently available.

Sodium-glucose co-transporter-2 inhibitors are a novel class of drugs with a novel mechanism of action, which can be useful in almost every stage of the natural history of diabetes, and represent a means of achieving better and safer glycemic control.

Sodium-glucose co-transporter-2 inhibitors can be used as initial monotherapy in persons in whom metformin is not indicated, or not tolerated. Examples include those with hepatic impairment and gastrointestinal intolerance. SGLT2i can also be used as second-line drugs, and third-line drugs, in persons inadequately controlled on a single or dual glucose-lowering therapy. Their glucose-lowering effect may help some people with diabetes delay insulin injections. Additionally, a significantly low risk of hypoglycemia with these agents can improve outcomes and compliance considerably.

The pleiotropic effects of SGLT2i-weight loss, BP reduction, and uricosuria-make them especially attractive for use in persons with metabolic syndrome, and in those with mild fluid overload. Their oral mode of administration may favor their use over the injectable glucagon-like peptide-1 receptor agonists. 
This class of drugs can also be used in combination with insulin, and its insulinsparing effect allows for more effective, welltolerated glycemic control, without weight gain. A 24-week clinical trial comparing dapagliflozin versus placebo in patients taking a high dose of insulin demonstrated a decrease in insulin requirement of $0.79 \%$ and $0.39 \%$, respectively [38]. Additionally, there was a significant decrease in insulin dose required by patients treated with dapagliflozin as compared to an increase in placebo group. A statistically significant decrease in body weight of up to $2.4 \mathrm{~kg}$ in the dapagliflozin $10 \mathrm{mg}$ group as compared to an increase of $0.43 \mathrm{~kg}$ in the placebo group was also seen [38].

The ability to prescribe SGLT2i to persons with renal [39] and hepatic impairment, an easy two-step or one-step dose titration, a lack of relevant drug-drug interactions, and safety in combination with all routinely used CV and anti-diabetic drugs, are all points which will encourage their use.

Counseling regarding potential side effects and ways to prevent them, for example, perineal hygiene and avoidance of volume depletion, must accompany SGLT2i prescription.

A recent pilot study explored the potential role of SGLT2i in managing hyperglycemia associated with type 1 diabetes mellitus (T1DM) [40]. This 2-week exploratory study of dapagliflozin in doses ranging from 1 to $10 \mathrm{mg}$ per day in addition to insulin, established its safety and pharmacokinetics, and explored the pharmacodynamics of a new class of drug for managing T1DM. Glucosuria increased by $88 \mathrm{mg} /$ day in the dapagliflozin group while it decreased by $21.5 \mathrm{mg} /$ day in the placebo group. Additionally, a fall of $16.2 \%$ in the dapagliflozin group and an increase of $1.7 \%$ in the placebo group for total daily insulin dose were seen during this period [40]. More proof-of-concept studies are available documenting renoprotection provided by these agents in T1DM. Renal hyperfiltration which is an early hemodynamic abnormality preceding frank nephropathy in T1DM was improved with short-term use of these agents [41, 42]. Newer SGLT2i, still in pre-clinical and clinical phases of development, are expected to have a safer profile in view of their highly selective action $[43,44]$.

\section{CONCLUSION}

The SGLT2i represent a novel class of drugs which will certainly help a large number of people with diabetes achieve target control in a safe and well-tolerated manner. Their unique mechanism of action, coupled with pleiotropic benefits on weight and blood pressure, should make them attractive choices for add-on therapy to persons not controlled on other medications.

\section{ACKNOWLEDGMENTS}

No funding or sponsorship was received for this study or publication of this article. Sanjay Kalra meets the ICMJE criteria for authorship for this manuscript, takes responsibility for the integrity of the work as a whole, and has given final approval for the version to be published.

Conflict of interest. Sanjay Kalra has received speakership honoraria from AstraZeneca for speaking on topics not related to the subject matter of this review.

Compliance with ethics guidelines. This review article is based on previously conducted studies, and does not involve any new studies of 
human or animal subjects performed by the author.

Open Access. This article is distributed under the terms of the Creative Commons Attribution Noncommercial License which permits any noncommercial use, distribution, and reproduction in any medium, provided the original author(s) and the source are credited.

\section{REFERENCES}

1. Abdul GM, DeFronzo R. Dapagliflozin for the treatment of type 2 diabetes. Expert Opin Pharmacother. 2013;14:1695-703.

2. Bailey CJ. Renal glucose reabsorption inhibitors to treat diabetes. Trends Pharmacol Sci. 2011;32:63-71.

3. Ehrenkranz J, Lewis N, Ronald KC, Roth J. Phlorizin: a review. Diabetes Metab Res Rev. 2005;21:31-8.

4. Wright EM. Renal Na+-glucose cotransporters. Am J Physiol Renal Physiol. 2001;280(1):F10-8.

5. Lee YJ, Lee YJ, Han HJ. Regulatory mechanisms of $\mathrm{Na}(+) / g l u c o s e$ cotransporters in renal proximal tubule cells. Kidney Int Suppl. 2007;(106):S27-35.

6. Hummel CS, Lu C, Loo DD, Hirayama BA, Voss AA, Wright EM. Glucose transport by human renal NA+/D-glucose cotransporters SGLT1 and SGLT2. Am J Physiol Cell Physiol. 2011;300:C721.

7. Nauck MA. Update on developments with SGLT2 inhibitors in the management of type 2 diabetes. Drug Des Devel Ther. 2014;8:1335-80.

8. Mudaliar S, Henry R, Boden G, et al. Changes in insulin sensitivity and insulin secretion with the sodium glucose cotransporter 2 inhibitor dapagliflozin. Diabetes Technol Ther. 2014;16:137-44.

9. Kasichayanula S, Liu X, LaCreta F, Griffen S, Boulton D. Clinical pharmacokinetics and pharmacodynamics of dapagliflozin, a selective inhibitor of sodium-glucose co-transporter type 2 . Clin Pharmacokinet. 2014;53:17-27.

10. Canagliflozin prescribing information, Janssen Pharmaceuticals. 2014. https://www.invokanahcp. com/prescribing-information.pdf.
11. Zhang L, Feng Y, List J, et al. Dapagliflozin treatment in patients with different stages of type 2 diabetes mellitus: effects on glycaemic control and body weight. Diabetes Obes Metab. 2010;12:510-6.

12. Lavalle-González FJ, Januszewicz A, Davidson J, et al. Efficacy and safety of canagliflozin compared with placebo and sitagliptin in patients with type 2 diabetes on background metformin monotherapy: a randomised trial. Diabetologia. 2013;56:2582-92.

13. Rohwedder K, Johnsson E, Parikh S. Reduced risk of hypoglycemic events with dapagliflozin vs. glipizide as add-on therapy in type 2 diabetes mellitus: 4-year data from a phase 3 study. In: Poster presented at 50th Annual meeting of the European Association for the Study of Diabetes. Vienna; 2014.

14. Rosenstock J, Jelaska A, Wang F, et al. Empagliflozin as add- on to basal insulin for 78 weeks improves glycemic control with weight loss in insulin-treated type 2 diabetes (T2DM). Can J Diabetes. 2013;37:S32.

15. Merovci A, Solis-Herrera C, Daniele G, et al. Dapagliflozin improves muscle insulin sensitivity but enhances endogenous glucose production. J Clin Invest. 2014;124:509-14.

16. Scheen A. Pharmacokinetic and pharmacodynamic profile of empagliflozin, a sodium glucose cotransporter 2 inhibitor. Clin Pharmacokinet. 2014;53(3):213-25.

17. Vasilakou D, Karagiannis T, Athanasiadou E, et al. Sodium-glucose cotransporter 2 inhibitors for type 2 diabetes: a systematic review and meta-analysis. Ann Intern Med. 2013;159:262-74.

18. Lambers Heerspink HJ, de Zeeuw D, Wie L, Leslie B, List J. Dapagliflozin a glucose-regulating drug with diuretic properties in subjects with type 2 diabetes. Diabetes Obes Metab. 2013;15:853-62.

19. Tikkanen I, Narko K, Zeller C, et al. Empagliflozin improves blood pressure in patients with type 2 diabetes (T2DM) and hypertension. In: Abstract 942 presented at the 49th European Association for the Study of Diabetes Annual Meeting, September 23-27, Barcelona, Spain. Diabetologia 2013;56:S377.

20. Weir MR, Januszewicz A, Gilbert RE, Lavalle Gonzalez FJ, Meininger G. Lower blood pressure (BP) with canagliflozin (cana) in subjects with type 2 diabetes mellitus (T2DM). Diabetes. 2013;62(Suppl 1):Abstract 1077-P.

21. Leiter LA, Yoon KH, Arias $\mathrm{P}$, et al. Canagliflozin provides durable glycemic improvements and body 
weight reduction over 104 weeks versus glimepiride in patients with type 2 diabetes on metformin: a randomized, double-blind, phase 3 study diabetes care. 2014. (pii: DC_132762). [Epub ahead of print].

22. Sha S, Devineni D, Ghosh A, et al. Pharmacodynamic effects of canagliflozin, a sodium glucose co-transporter 2 inhibitor, from a randomized study in patients with type 2 diabetes. PLoS One. 2014;9:e105638.

23. Hach T, Gerich J, Salsali A et al. Empagliflozin improves glycaemic parameters and cardiovascular risk factors in patients with type 2 diabetes (T2DM): pooled data from four pivotal phase III trials. Diabetologia 2013;56(Suppl 1):S377 (Abstract 943).

24. Del Prato S, Nauck MA, Durán-Garcia S, et al. Durability of dapagliflozin vs. glipizide as add-on therapies in T2DM inadequately controlled on metformin: 4-year data [Abstract]. http://www. abstractsonline.com/Plan/ViewAbstract.aspx?sKey= 0687e7c8-c97d-442b-92ec-ae505e051854\&cKey= 9bb1b5dd-fbfe-4de6-9b27-054820e39f63\&mKey= \{89918D6D-3018-4EA9-9D4F-711F98A7AE5D\}. Accessed 14 Nov 2014.

25. Ptaszynska A, Johnsson KM, Parikh SJ, de Bruin TW, Apanovitch AM, List JF. Safety profile of dapagliflozin for type 2 diabetes: pooled analysis of clinical studies for overall safety and rare events. Drug Saf. 2014;37:815-29.

26. Neal B, Perkovic V, de Zeeuw D, et al. Rationale, design, and baseline characteristics of the Canagliflozin Cardiovascular Assessment Study (CANVAS): a randomized placebo-controlled trial. Am Heart J. 2013;166:217-223 e11.

27. Bolinder J, Ljunggren, Johansson $\mathrm{L}$, et al. Dapagliflozin maintains glycaemic control while reducing weight and body fat mass over 2 years in patients with type 2 diabetes mellitus inadequately controlled on metformin. Diabetes Obes Metab. 2014;16:159-69.

28. Ruggenenti P, Porrini Esteban L, Gaspari F, Motterlini N, et al. Glomerular hyperfiltration and renal disease progression in type 2 diabetes. Diabetes Care. 2012;35:2061-8.

29. Dapagliflozin prescribing information, AstraZeneca Pharmaceuticals. 2014.

30. Fujita Y, Inagaki N. Renal sodium glucose cotransporter 2 inhibitors as a novel therapeutic approach to treatment of type 2 diabetes: clinical data and mechanism of action. J Diabetes Invest. 2014;5:265-75.

31. Rossenwasser RF, Sultan S, Sutton D, Choksi R, Epstein BJ. SGLT-2 inhibitors and their potential in the treatment of diabetes. Diabetes Metab Syndr Obes. 2013;6:453-67.

32. Sarnoski-Brokavich S, Hilas O. Canagliflozin (invokana), a novel oral agent for type-2 diabetes. P T. 2013;38:665-6.

33. Johnsson Kristina M, Ptaszynska Agata, Schmitz Bridget, Sugg Jennifer, et al. Vulvovaginitis and balanitis in patients with diabetes treated with dapagliflozin. J Diabetes Complicat. 2013;27:479-84.

34. Kalra S, Baruah MP, Sahay R. Medication counselling with sodium glucose transporter 2 inhibitor therapy. Indian $\mathrm{J}$ Endocrinol Metab. 2014;18:597-9.

35. Stenlof K, Cefalu WT, Kim KA, et al. Long-term efficacy and safety of canagliflozin monotherapy in patients with type 2 diabetes inadequately controlled with diet and exercise: findings from the 52-week CANTATA-M study. Curr Med Res Opin. 2014;30:163-75.

36. Ferrannini E, Berk A, Hantel S, et al. Long-term safety and efficacy of empagliflozin, sitagliptin, and metformin: an active-controlled, parallel-group, randomized, 78-week open-label extension study in patients with type 2 diabetes. Diabetes Care. 2013;36:4015-21.

37. Empagliflozin. www.clinicaltrials.gov. U.S. National Institutes of Health. Retrieved May 8, 2014.

38. Wilding JP, Woo V, Soler NG, et al. Long-term efficacy of dapagliflozin in patients with type 2 diabetes mellitus receiving high doses of insulin: a randomized trial. Ann Intern Med. 2012;156:405-15.

39. Ptaszynska A, Mansfield T, Johnsson E, Parikh SJ, Yavin Y, List JF. Long-term renal Safety with dapagliflozin treatment. In: Poster presented at 50th Annual meeting of the European Association for the Study of Diabetes. Vienna; 2014.

40. Henry RR, Rosenstock J, Edelman S, et al. Exploring the potential of the SGLT2 inhibitor dapagliflozin in type 1 diabetes: a randomized, double-blind, placebo-controlled pilot study. Diabetes Care. 2014. (pii:DC_132955) [Epub ahead of print].

41. Cherney DZ, Perkins BA, Soleymanlou N, et al. Renal hemodynamic effect of sodium-glucose cotransporter 2 inhibition in patients with type 1 diabetes mellitus. Circulation. 2014;129:587-97.

42. Cherney DZ, Perkins BA. Sodium-glucose cotransporter 2 inhibition in type 1 diabetes: simultaneous glucose lowering and renal protection. Can J Diabetes. 2014;38:356-63. 
43. Nagata T, Fukazawa M, Honda $K$, et al. Selective SGLT2 inhibition by tofogliflozin reduces renal glucose reabsorption under hyperglycemic but not under hypo-or euglycemic conditions in rats. Am J Physiol Endocrinol Metab. 2013;304:414-23.
44. Ohtake Y, Sato T, Kobayashi T, et al. Discovery of tofogliflozin, a novel C-arylglucoside with an O-spiroketal ring system, as a highly selective sodium glucose cotransporter 2 (SGLT2) inhibitor for the treatment of type 2 diabetes. J Med Chem. 2012;55:7828-40. 